\title{
SOME CONSIDERATIONS CONCERNING THE ESTABLISHMENT OF OPTIMUM PLOT SIZE IN FOREST SURVEY \\ By GILBERT TARDIF ${ }^{1}$
}

\section{INTRODUCTION}

Among the various operations involved in the preparation of forest maps and statistics of a given area, the forest survey is certainly one of the most difficult as well as the most important one.

During the recent years many technological and methodological advances have contributed greatly to facilitate the execution of forest surveys. Among these we may enumerate:

- The use of aerial photography which, by allowing us to identify and stratify the forest area, permits us to realize more efficient sampling designs. Moreover, the use of aerial photography is of great help in locating the best access roads to the forest and the sample plots. The research presently conducted in the field of large scale aerial photography whereby the height and crown measurements as well as the tree count per acre could be recorded in order to establish the tree volume and the volume per acre constitute another promising application of aerial photography and a significant advance towards reduction of field work.

- The establishment of continuous inventory control systems involving the setting up of permanent sample plots in conjunction with non-permanent sample plots allows us to jointly make timber volume evaluation as well as silvicultural studies.

- The use of relascope which considerably simplifies the field data collection and office compilation. The use of this instrument is, however, restricted to certain types of forests and certain categories of survey.

- Finally, the processing of survey data with high speed computer has partly eliminated the technical and clerical efforts, increased the reliability of information and opened a great number of possibilities for compiling new forest statistics.

Among the many other factors that may affect the cost as well as the value and accuracy of forest survey data are certainly the sampling design and the form and surface of the sample plots. These two interrelated factors may affect the cost or efficiency (relative cost per unit of information) of a survey in the following manner:

$$
\text { Sampling design }
$$

- defines the selection method as well as the location of sample in the field. It affects the access to the sample plots (sample plots are easier to locate in systematic than in simple random sampling) as well as the amount of displacement and travelling.

- determines the size of the sample. In this, it influences

i) the time and cost of collecting and processing survey data.

ii) the amount of travelling between the sample plots.

- determines the ability of sample data to provide an estimate of the sampling error.
Size and form of sample plots

- THE SIZE: it takes relatively more small sample plots than larger ones to establish sample estimates with some preassigned precision level. Therefore the displacement or travelling is greater with smaller sample plots.

- THE FORM: the form may affect considerably the time for laying down the plot and data collection and the occurrence of errors of observations (including or excluding the peripheral trees, etc.) The form of the plot may also affect the size of the cruising party.

${ }^{1}$ Omer Lussier Associates, 870 Casot Ave., Quebec, P.Q. 
Even if these two factors are, to some extent, interrelated, this paper will be confined to some aspects of the establishment of the optimum size of sample plots.

This question will be studied in the light of data provided by a $100 \%$ intensity cruise of a 50-acre forest area. This survey has been performed by Mr. Pierre Villeneuve in the course of the preparation of his M.Sc. degree at Laval University. We are indebted to Mr. Villeneuve for some of the calculations and figures presented in this paper.

\section{DESCRIPTION OF THE FOREST}

The stand or stands selected for this particular experience is located in the "Forêt Domaniale de Matane", a crown territory located approximately at 250 miles northeast of Quebec City.

This particular territory belong to the mixed-wood forest and is mainly composed of balsam fir and white birch. The forest was further classified according to ecological types. These types indicated a site class number one. The following ecological types and their respective area and age classes are presented below.

To further characterize this forest, it is appropriate to mention that it has been subjected - on a few sections of the territory - to partial cutting at times.

TABLE 1

List of the Various Strata of THe Forest and Their Respective Areas

\begin{tabular}{lllcc}
\hline $\begin{array}{c}\text { Forest } \\
\text { types }\end{array}$ & $\begin{array}{c}\text { Age } \\
\text { Classes }\end{array}$ & \multicolumn{1}{c}{ Strata } & $\begin{array}{c}\text { Namber of } \\
\text { 1/20-acre plota }\end{array}$ & $\begin{array}{c}\text { Area } \\
\text { (acrea) }\end{array}$ \\
\hline Dryopteris-Oxalis & 90 & Dry-OX-90 & 137 & 6.85 \\
Dryopteris-Oxalis & 70 & Dry-OX-70 & 659 & 32.95 \\
Dryopteris-Oxalis & 50 & Dry-OX-50 & 5 & 0.25 \\
Dryopteris-Oxalis & $30-70$ & Dry OX-30-70 & 56 & 2.8 \\
Dryopteris-Oxalis & 30 & Dry-OX-70 & 11 & 0.55 \\
Hylocomium-Oxalis & 70 & Hy-OX-70 & 67 & 3.35 \\
Hylocomium-Cornus & 70 & Hy-CO-70 & 21 & 1.05 \\
\hline
\end{tabular}

For the purpose of some of our experiments, some of the smaller strata were regrouped into larger units.

\section{The Data Collection and Compilation}

Basic plots of $1 / 20$ acre were used for the field collection of data. Each plot was identified as to the forest type and age class, thus allowing the stratification of the forest in strata defined by the forest type and the age class. The volume of each plot was computed and the average volume as well as the variance for each stratum and for the forest as a whole was computed. The results are presented in Table 2 below. 
TABLE 2

Parameters of Each StRatum

\begin{tabular}{lcccc}
\hline \multicolumn{1}{c}{ Strata } & $\begin{array}{c}\text { Number of } \\
\text { 1/20-acre plots }\end{array}$ & $\begin{array}{c}\text { Average vol. } \\
\text { per plot (co. ft.) }\end{array}$ & Variance & $\begin{array}{c}\text { Coefficient of } \\
\text { variation (\%) }\end{array}$ \\
\hline Dry-OX-90 & 137 & 175 & 3711 & 35 \\
Dry-OX-70 & 659 & 206 & 3522 & 28 \\
Dry-OX-50 & 5 & 57 & 567 & 42 \\
Dry-OX-30-70 & 56 & 90 & 1094 & 37 \\
Dry-OX-30 & 11 & 43 & 1313 & 83 \\
Hy-OX-70 & 67 & 237 & 2739 & 22 \\
Hy-CO-70 & 21 & $\underline{222}$ & $\underline{1406}$ & $\mathbf{1 6}$ \\
$\quad$ Total & $\mathbf{9 5 6}$ & $\mathbf{1 9 5}$ & $\mathbf{4 5 7 7}$ & $\mathbf{3 5}$ \\
\hline
\end{tabular}

This basic information being compiled, it is now possible to consider in some detail the problems of the determination of the size of the sample plot.

\section{The Determination of the Size of the Sample Plot}

Some experiments and project research have been conducted on this topic in different countries of the world. A review of these various contributions leads to the following conclusions.

- all authors are unanimous in saying that the size and form of sample plots may influence greatly the efficiency (number of plots to obtain an estimate with a given precision level), the accuracy of data and the cost of the survey.

- the size and form of the sample plor should be a function of the nature of the stand, the larger plots being used in mature low density stands while emaller plots will be appropriate in younger and higher density stands.

- plot a reas ranging from $1 / 10$ to 1 acre are generally recommended.

- concerning the shape of the plots,

i) certain authors recommend relatively long and narrow plots with the longer axis located in the direction of the gradient of fertility in order to include as much variation as possible within each plot.

ii) others recommend large and relatively short plots to avoid overlapping over many forest types.

iii) finally others recommend circular plots.

- no general and analytical methods have been yet devised that allow to determine the optimum plot size in a given type or group of types of forest.

As it clearly appears, the question therefore remains opened for further discussion and research. The purpose of the experiment under discussion is precisely to pursue further some of the aforementioned experiments and attempt to utilize an analytical approach to this problem of the optimum sample plot determination.

\section{The analytical procedures}

In order to outline or devise an analytical procedure for determining the optimum size of the sample plot it is essential to state or define an optimality criterion. For the purpose of our analysis the following criterion was selected: "For a given preassigned precision level of the volume estimate and a given forest type or a group of forest types find the plot size that will minimize the total cost of the forest survey". 
Following this statement, two basic relationships ought to be established:

- the relationship between the precision of the sample estimate and the size of the plot.

- the relationship between the cost of the survey and the size of the plot.

In order to develop these two functions, let us define the following terms, assuming a simple random sampling design.

$\overrightarrow{\mathrm{x}}_{1}=$ volume of the i-th plot.

$n=$ number of plots in the sample.

$\mathrm{N}=$ total number of plots in the forest area to be surveyed.

$\vec{x}=$ estimate of the average volume per plot.

$S^{\mathbb{a}}=$ variance estimate of the volume.

$\mathrm{C}_{\mathrm{v}}=\frac{\mathrm{S}}{\overline{\mathrm{x}}}$ coefficient of variation.

$\mathrm{K}=$ admissible error in the estimation of the average volume.

Let us consider now each of the above mentioned relationships.

A) The relationship between the precision of the sample estimate and the size of the plot.

The total number of sample plots necessary to obtain an estimate, $\bar{x}$, whose sampling error will not be greater than $\mathrm{K}$ at the $\mathbf{P}$ probability level is given by the expression:

$\mathrm{n}=\frac{\mathrm{t}_{\mathrm{p}}^{2}}{\mathrm{k}^{2}} \quad \frac{s^{2}}{\vec{x}^{2}}=\frac{\mathrm{t}_{\mathrm{p}}^{2} \mathrm{C}_{\mathrm{v}}^{2}}{\mathrm{~K}^{2}}$

where $t_{p}$ is the Student's $t$ at the $P$ probability level.

From (1) we obtain:

$\mathrm{K}=\frac{\mathrm{t}_{\mathrm{p}}}{\sqrt{\mathrm{n}}} \frac{\mathrm{s}}{\bar{x}}=\frac{\mathrm{t}_{\mathrm{p}}}{\sqrt{\mathrm{n}}} \quad \mathrm{C}_{\mathrm{v}} \quad$ (considering the absolute value only)

Now $c_{\mathrm{v}}$ is a function of the size of the sample plot. Let $y$ be the variable representing the relative size of the plot and $g(y)$ the function describing the relationship between $\mathrm{C}_{\mathrm{v}}$ and $\mathrm{y}$.

$$
\begin{aligned}
& \mathrm{C}_{\mathrm{v}}=\mathrm{g}(\mathrm{y}) \\
& \text { and by substitution in (1) } \\
& \mathrm{K}=\frac{{ }^{\mathrm{t}} \mathrm{g}(\mathrm{y})}{\sqrt{\mathrm{n}}}
\end{aligned}
$$

In order to develop the function $\mathrm{g}(\mathrm{y})$, the coefficient of variation $\mathrm{C}_{\mathrm{r}}$ has been computed for five different sizes of plots, namely $1 / 20,1 / 10,1 / 5$, $1 / 4$ and $3 / 10$ of an acre in stratum Dry-OX-70. Due to insufficient number of plots, these calculations have not been performed in other strata. 
TABLE 3

Coefficient of Variation for Various Size of Plots IN STRatum DRY-OX-70

\begin{tabular}{ccc}
\hline Size of plot & $\begin{array}{c}\text { Relative size of } \\
\text { sample plot }(\mathbf{y})\end{array}$ & $\begin{array}{c}\mathbf{C}_{\mathbf{v}} \\
(\boldsymbol{\%})\end{array}$ \\
\hline $1 / 20$ & 1 & 28.0 \\
$1 / 10$ & 2 & 24.0 \\
$1 / 5$ & 4 & 19.4 \\
$1 / 4$ & 5 & 18.4 \\
$3 / 10$ & 6 & 17.3 \\
\hline
\end{tabular}

By plotting the coefficient of variation as a function of size of plots (see figure 1 below), it appears that $g(y)$ is of the form

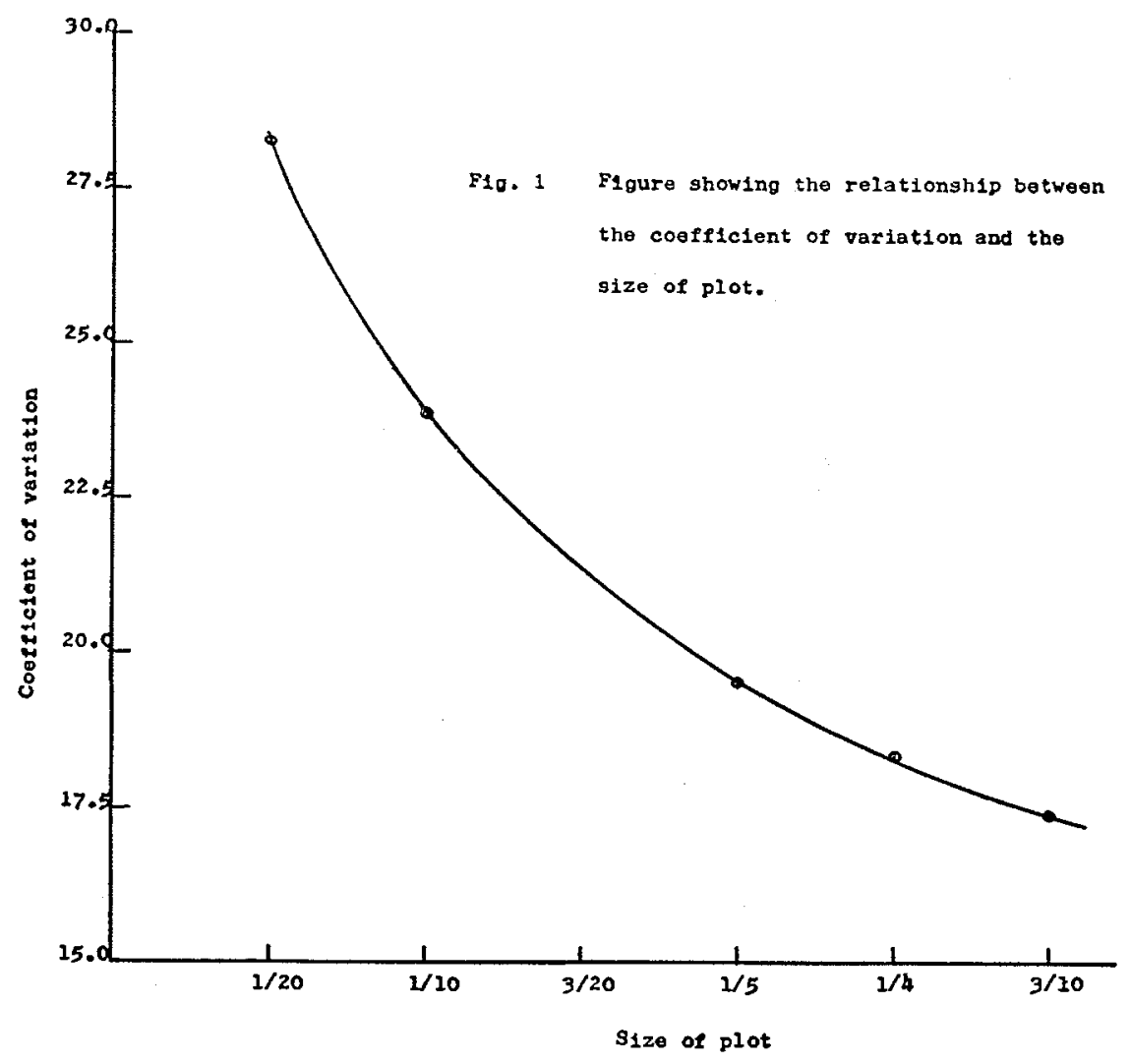


$g(y)=a y^{-g}$

where $y$ is the relative size of plots

a, $g$, are parameters that are determined by Least Squares methods.

Using data of Table 3, estimate of $a$ and $b$ are found to be:

$\mathrm{a}=0.2835$

$\mathrm{g}=0.27085$

and

$g(y)=0.2835 / y^{0.27085}$

Using this equation we may compute values of the coefficient of variation $\mathrm{g}(\mathrm{y})$, corresponding to plot sizes of $1 / 20,1 / 10,1 / 5,1 / 4$, and $3 / 10$. These calculated $\mathrm{g}(\mathrm{y})$ are presented in Table 4 below. These calculated and observed values compare very closely.

TABLE 4

Comparative List of Observed and Calculated Values of The STANDaRd DeViations

\begin{tabular}{ccc}
\hline $\begin{array}{c}\text { Size of } \\
\text { sample plot }\end{array}$ & $\mathbf{y}$ & $\begin{array}{c}\text { calculated coefficient } \\
\text { of variation, } \mathbf{C}_{\mathbf{v}}(\%)\end{array}$ \\
\hline $1 / 20$ & 1 & 28.3 \\
$1 / 10$ & 2 & 23.5 \\
$1 / 5$ & 4 & 19.5 \\
$1 / 4$ & 5 & 18.3 \\
$3 / 10$ & 6 & 17.4 \\
\hline
\end{tabular}

B) The relationship between the cost of sampling and the size of the plots.

The cost of sampling in a forest survey is made up of two main components, namely:

- the cost of data collecting proper which on a per plot basis is more or less proportional to the size of the plot.

- the cost of displacement or travelling between the plots. This cost depends on the sampling plan, the average distance between plots, the nature of forest and terrain and the accessibility of the area to be surveyed.

i) The cost of data collecting,

The total cost of data collecting in a survey is equal to: $\mathrm{yc}_{1} \mathrm{~m}$

where

$c_{1}$ is the cost of surveying one basic plot of relative size 1 , that is $1 / 20$ acre.

$\mathrm{y}$ and $\mathrm{n}$ in this example, have same signification as before.

ii) The cost of travelling,

This cost component will vary with:

- the size of the sample, $n$

- the sampling intensity, that is the ratio $\mathrm{D} / \mathrm{N}$ of sample size to the total number of plots

- the sampling design

- the nature of terrain, the accessibility, etc.

Research done in agricultural survey by Mahalanobis (1944) ${ }^{2}$ and Jessen (1942) ${ }^{3}$ indicates that for a fixed area and in simple random sampling, the total travelling distance $d_{o}$ between points or plots is proportional to the square root of the sample size, $n$,

$$
\mathrm{d}_{\mathrm{o}}=\mathrm{b} \vee \mathrm{n}
$$


Where $b$ is the coefficient of proportionality. If, $c_{2}$ is the travelling cost per unit distance, then the total travelling cost for a fixed area is $c_{2} b V \mathrm{n}$. Now it is interesting to see how the total distance, $d_{o}$, would vary when n plots are allocated to a territory whose surface is some multiple, $\mathrm{m}$, of the basic area for which $d_{o}$ has been computed. Let assume that the basic area is unity and this geometric configuration does not depart too much from the square. The side of this square is unity and the side of a square whose surface is twice $(m=2)$ as large is 1.43. Therefore doubling the surface of the unit square increases the length of their sides (and the average distance between any two points or plots in that area) by the amount of $1.43 / 1=\mathrm{m}$.

Therefore the total travelling distance, $d$, between points or plots located in a territory whose area is some multiple, $\mathrm{m}$, of the basic area for which $\mathbf{d}_{o}$ has been established should be approximately equal to (provided the geometric figure does not depart too significantly from the square)

$$
\mathrm{d}=\mathrm{d}_{\mathrm{o}} \vee \mathrm{m}=\mathrm{b} \vee \mathrm{nm}
$$

Under these assumptions the total travelling cost is equal to $\mathrm{bc}_{2} \vee \mathrm{nm}$

The total cost of sampling, $c_{0}$, is thus equal to

$$
c_{0}=c_{1} n y+b c_{2} \vee n m
$$

C) The determination of the optimum plot size

The relationships defining the precision of the volume estimate (eq. 3) and the cost of the forest survey (eq. 9) as a function of the size of the plot being established, it is possible to determine the optimum size of the plot. Essentially, the problem is one of minimizing a mathematical function subject to a constraint. In this particular instance, our objective is to determine a plot size that will minimize the total sampling cost for a fixed sample size (or a sample size that will assure some preassigned precision level).

The minimization process is accomplished by forming the function

$$
\mathrm{F}=\mathrm{c}_{1} \mathrm{ny}+\mathrm{bc}_{2} \sqrt{\mathrm{nm}}+\lambda \frac{\mathrm{t}_{\mathrm{p}} \text { ay- }}{\sqrt{\mathrm{n}}}-\mathbf{k}
$$

Where $\lambda$ is the Lagrange's multiplier. The optimum plot size is obtained in setting equal to zero and solving the partial derivatives of (10) in respect to $\mathrm{y}, \mathrm{n}$ and $\lambda$.

$$
\begin{aligned}
& \frac{\delta F}{\delta y}=o=c_{1} n-\frac{\lambda c_{p} a y^{-g}-1}{V_{n}} \\
& \frac{\delta F}{\delta n}=0=c_{1} y+\frac{b c_{2} V_{m}}{2 V_{n}}-\frac{\lambda t_{p} a y^{-g}}{2 n^{8 / 2}} \\
& \frac{\delta F}{\delta \lambda}=o=\frac{t_{p} a y^{-g}}{\sqrt{n}}-K
\end{aligned}
$$

- MaHalanOBIS, P. C. (1944): On Large-Scale Sample Survey, Phil. Trans. Roy. Soc. London, Series B. 231, 329-451.

- JESSEN, R. (1942): Statistical Investigation of a Sample Survey for Farm Facts, Research Balletin 304, Agricultural Exp-Sta. Iowa State College, Iowa. 
The solution is:

$y=\left(c_{2} / c_{1}\right)$ bgk $\vee \mathrm{m}$

$\frac{\text { atp }(1-2 g)}{1-2}$

$$
\log y=\frac{\log \left(\mathrm{c}^{2} /{ }_{\mathrm{c}^{1}}\right)+\log (\mathrm{bgk} \sqrt{\mathrm{m}})-\log \left[a t_{\mathbf{p}}(1-2 \mathrm{~g}]\right.}{1-\mathrm{g}}
$$

The absolute value of $\mathrm{g}$ is to be used all along in this equation.

As indicated before, " $y$ " is the relative size of the plot in respect to the basic $1 / 20$-acre plot. In this equation,

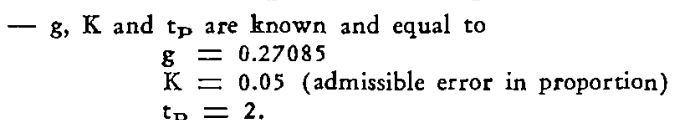

$$
\mathrm{t}_{\mathrm{p}}=2 \text {. }
$$

$-b, c$, and $c_{2}$ are parameters that are to be determined from experience. As estimates of these parameters are not available certain number of values have been substituted in order to see how the value of $y$ would be affected by changes in $b$ and in the ratio $c_{2} / c_{1}$.

- $m$ is equal to 1 for the basic area or territory used in determining the basic relationship.

$$
\mathrm{d}_{\mathrm{o}}=\mathrm{d} \mathrm{V}^{\mathrm{a}}
$$

For any other area, $\mathrm{m}$ is the ratio of its surface to the one of the basic area. Values of $m$, of 1 and 2 will be explored here.

The results of these calculations are shown in table 5 below and figures 2 and 3.

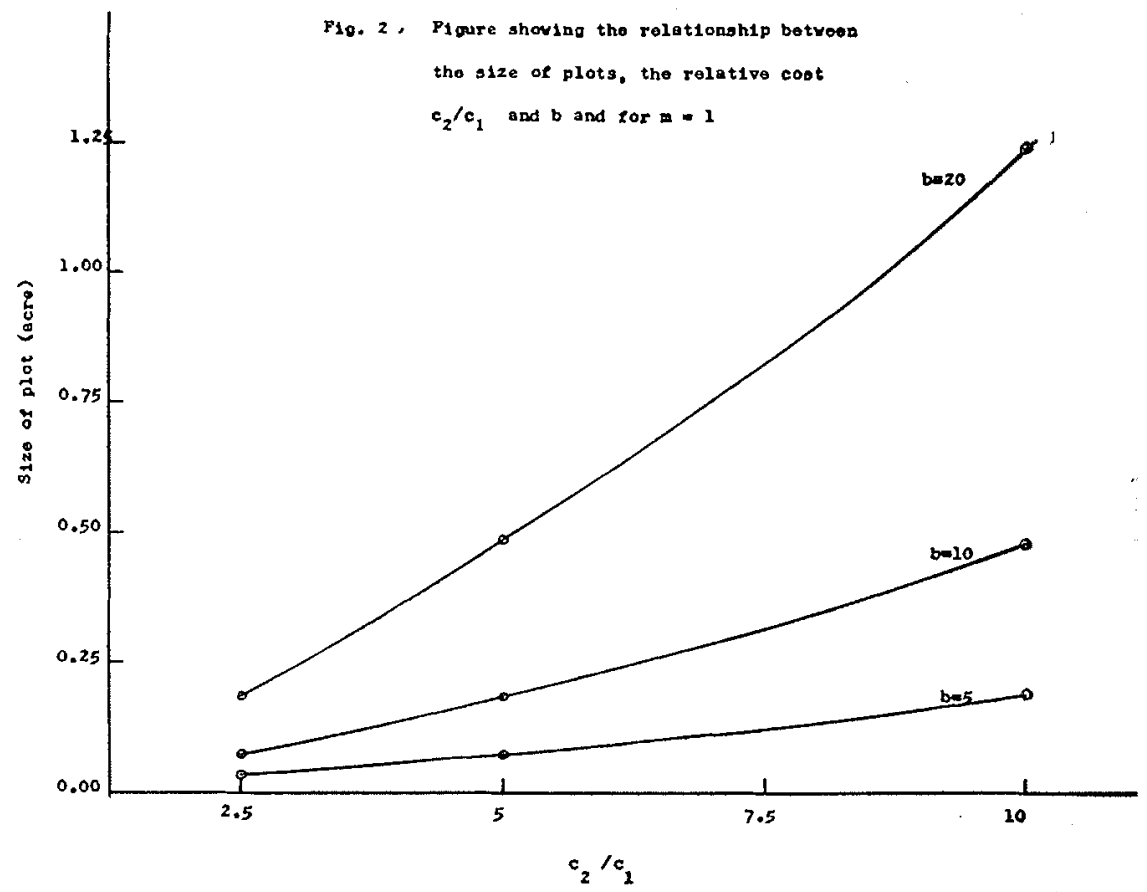




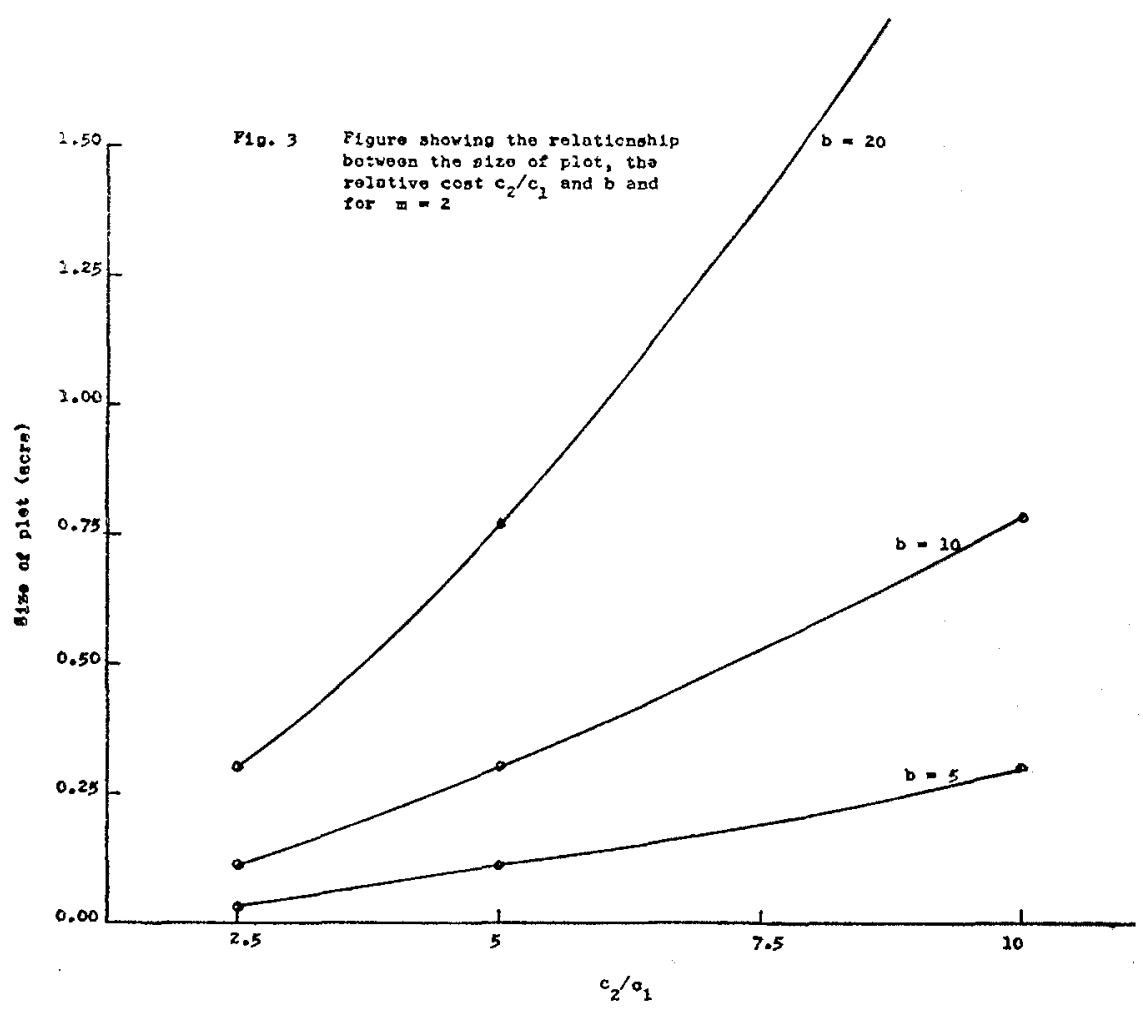

TABLE 5

Table Showing the Values of y as a function of $c_{2} / c_{1}$, b and $m$

\begin{tabular}{|c|c|c|c|c|c|c|c|}
\hline \multicolumn{4}{|c|}{ m equals 1} & \multicolumn{4}{|c|}{ m equals 2} \\
\hline$\overline{c_{8} / c_{1}}$ & b & $\mathbf{y}$ & $\begin{array}{c}\text { Size of } \\
\text { plot (acre) }\end{array}$ & $\overline{c_{2} / c_{1}}$ & b & $y$ & $\begin{array}{c}\text { Size of } \\
\text { plot (acre) }\end{array}$ \\
\hline 2.5 & 5 & 0.554 & 0.027 & 2.5 & 5 & 0.629 & 0.031 \\
\hline 2.5 & 10 & 1.436 & 0.072 & 2.5 & 10 & 2.347 & 0.117 \\
\hline 2.5 & 20 & 3.717 & 0.186 & 2.5 & 20 & 6.070 & 0.303 \\
\hline 5 & 5 & 1.436 & 0.072 & 5 & 5 & 2.347 & 0.117 \\
\hline 5 & 10 & 3.717 & 0.186 & 5 & 10 & 6.070 & 0.303 \\
\hline 5 & 20 & 9.619 & 0.481 & 5 & 20 & 15.710 & 0.785 \\
\hline 10 & 5 & 3.717 & 0.186 & 10 & 5 & 6.070 & 0.303 \\
\hline 10 & 10 & 9.619 & 0.481 & 10 & 10 & 15.710 & 0.785 \\
\hline 10 & 20 & 24.887 & 1.244 & 10 & 20 & 40.640 & 2.030 \\
\hline
\end{tabular}


It is seen from table 5 and figures 2 and 3 that the relative size of the plots is affected in a very significant manner:

- by the relative cost $c_{2} / c_{1}$ that is the cost of travelling per unit distance to the cost of collecting data on a basic plot of relative size 1 . The ratio of this cort will probably be specific to broad classes of forest types. As the ratio increases the size of the plot should be enlarged; this is plausible, for, if the cost of travelling is high the travelling distance should be reduced by enlarging the size of plots and decreasing their number.

- by the coefficient of proportionality, $b$, which in the relationship $\mathrm{d}_{0}=\mathrm{d} \sqrt{ } \mathrm{n}$

determines the total travelling distance in the basic area. For fixed sample size, n is proportional to the magnitude of the basic area. Thus, the value of $y$ increases as $b$ increases.

- by the coefficient $m$, where $m$ is the ratio of the area of some territory to the basic area. $m$ is but a correction to $b$ and influences $y$, in the same way.

\section{CONCLUSION}

A simple method has been studied in order to determine the optimum plot size in forest inventories. The approach, at this stage of development, even if it appears quite academical by nature, nevertheless confirms the conclusions of many authors who all agree that the size of the plots should be tailored to the type of the stand.

The proposed analytical method, we believe, is quite general and may apply to many specific cases, some of the hypothesis, however, should be verified and tested, namely

- the structure of the relationship defining the total travelling distance in a fixed area.

- the relationship defining the increase in total travelling distance when the surface of the "fixed area" is increased.

- finally the structure of $g(y)$ for values of $y$ outside of the range of observed values.

Furthermore, research should be done and information gathered concerning:

- the cost of data collecting and travelling in typical forest strata.

- the effect of sampling design on total travelling distance.

-- the effect of the shape of plots on cost of recording data and errors of observations.

The results of this research should lead to the definition of the optimum plot size for a few significant forest strata. Even if theoretically it is appropriate to change the plot size according to the nature of stands, the size of the forest area, etc., the utilization of a large array of sizes of sample plot would, in practice, be difficult to administer and might eventually defeat the ultimate objective of reducing the cost of inventory. 